\title{
ROBERTO BOLAÑO \\ Y WITOLD GOMBROWICZ: \\ DOS REBELDES DE LAS LETRAS
}

\author{
Natalia Sadowska \\ Universidad de Łódź \\ Departamento de Filología Hispánica
}

\begin{abstract}
Resumen. El objetivo del presente trabajo consiste en aportar ejemplos que sean una clara muestra de conexiones entre las letras polaca e hispana, en este caso, encarnadas por dos escritores conocidos por el carácter rebelde de sus poéticas y la leyenda urbana de autores controvertidos que se creó en torno a sus vidas: el chileno Roberto Bolaño y el polaco Witold Gombrowicz. Con dicho propósito, el estudio propone un acercamiento a la vida y la obra de ambos autores con el fin de indicar lazos, tanto de carácter literario como biográfico, que unen a Bolaño y Gombrowicz, siendo a la vez el vínculo entre las mencionadas literaturas.
\end{abstract}

Palabras clave: Bolaño, Gombrowicz, literatura comparada, extraterritorialidad, autoficción.

\section{ROBERTO BOLAÑO AND WITOLD GOMBROWICZ: THE REBELS OF LITERATURE}

\begin{abstract}
The aim of the present work is to provide examples which are clear illustration of the connection between Polish and Hispanic literature, in this case incarnated by the figures of Roberto Bolaño and Witold Gombrowicz: two writers known for the rebellious nature of their poetics and the urban legend of controversial which was created around their lives.
\end{abstract}


Therefore, the following work proposes the approach to the life and work of both authors with the purpose of indicate relations between them, both literary and biographical, thus prove the connections which exist between Polish and Spanish letters.

Keywords: Bolaño, Gombrowicz, comparative literature, extraterritoriality, autofiction.

A primera vista, parece casi imposible encontrar lazos -que sean lo suficientemente fuertes- entre la obra y la vida de Roberto Bolaño y Witold Gombrowicz. Como los principales obstáculos, habrá que indicar la distancia temporal que separa a ambos autores y las considerables diferencias entre las tradiciones literarias de las que provienen. Empero, es bien sabido que Bolaño conocía y apreciaba la obra gombrowicziana cuyo testimonio encontramos en Entre paréntesis, un conjunto de ensayos donde Bolaño varias veces menciona al escritor polaco en diversos contextos e, incluso, dedica uno de los textos a la traducción catalana de Ferdydurke ("Ferdydurke en catalán”) que, desde su punto de vista, es "[...] uno de los libros más luminosos de este siglo más bien lleno de claroscuros" (Bolaño, 2004: 117). Pese a ello, resulta imposible afirmar con certeza si la obra gombrowicziana dejó huella en el estilo literario del chileno. No obstante, Ricardo Piglia, en la conferencia ofrecida en la Universidad Diego Portales de Chile titulada "El escritor como lector", declaró que "hay una relación entre la mirada de Gombrowicz y la mirada de Bolaño". Dicha mirada se refiere a la poética de ambos escritores y al carácter transgresivo tanto de la obra bolañiana como de la gombrowicziana - de ahí surgen las primeras similitudes de carácter formal.

La escritura del chileno pertenece a la llamada metaficción que juega con las perspectivas narrativas, intercalando personajes reales e históricos pasados o actuales, poniendo en duda la identidad subjetiva del narrador y entremezclando la realidad con la ficción. Bolaño rotundamente niega la existencia de una verdad absoluta y unívoca propia de mímesis, demostrando mediante la fragmentación, la alternancia temporal, la fractalización de las voces y la 
infinitización de los discursos que un suceso o personaje siempre tienen varias caras y múltiples matices. "Nos enfrentamos así, a huellas, fragmentos discursivos que no pueden construir la presencia sino solo rondarla, rozarla para, en el mismo acto, desviarse de su espejo, impidiendo la reproducción del original y los pactos de mímesis con el lector" (Espinosa Hernández, 2003: 20). Como ha sido mencionado, el chileno acude a la temática histórico-política para convertirla en el fondo - un fondo adaptable que está al servicio de la literatura- y referente de sus narraciones, aunque afirma que la estructura siempre es más importante que el argumento: "[...] lo que permite que el árbol, si aceptamos darle esa figura a la experiencia literaria, se mantenga vivo y no se seque es la estructura, nunca el argumento. [...] La estructura es la música de la literatura" (Swinburn, 2003). Por tanto, emplea un abanico de técnicas metaliterarias -el mundo de los poetas, distintos movimientos literarios, figura del escritor, reflexión acerca de la crítica literaria desde la mirada histórica, sociológica y psicológica- para introducir nuevos sentidos, huellas intertextuales, configuraciones del sujeto y modificaciones de motivos y objetivos. En otras palabras, la recurrente heterogeneidad de perspectivas, tendencia a entretejer discursos y desestabilizar al protagonista están presentes en su producción literaria.

Celina Manzoni emplea la metáfora de la tauromaquia introducida por Michel Leiris en 1946 para expresar la peculiaridad del estilo bolañiano donde se cruzan estéticas subvaloradas por la crítica contemporánea:

Su proyecto de escritura, sustentado en la pasión de contar, propone una poética en la que confluyen y se cruzan con libertad, formas culturales que de manera tradicional han sido catalogadas y discriminadas por su condición, de "cultas" o de "populares". Al mismo tiempo se proponen preguntas que [Bolaño] resuelve con originalidad y audacia: de qué manera la ficción puede contar lo político, cómo narrar el horror, cómo construir una memoria y una escritura que trastornen los límites entre lo manifiesto y lo subyacente (Manzoni, 2006: 14). 
Así pues, las propuestas de Bolaño transforman la tradicional heterogeneidad y se oponen a lo estereotípico, trastornando el orden consagrado por la academia y el mercado literario que se manifiesta en optar por el ya anticuado y acabado Realismo mágico, en simplificación y banalidad de la literatura y sus recursos con el objetivo de adaptarse a un público masivo. La hibridez de su narrativa se demuestra en los giros argumentales inesperados, el experimentalismo formal, el mezclar de distintos códigos lingüísticos (desde el tono culto hasta el argot callejero) y, finalmente, en la convivencia de personajes de todas clases sociales (escritores famosos, burguesía, clase media, pero también prostitutas y el lumpen). En este contexto, los textos del autor chileno pueden ser denominados como anticanónicos. Numerosos críticos literarios hablan de una nueva estética creada por Bolaño que supera las mencionadas modalidades tradicionales, siendo "una búsqueda de incorporación de lo político a registros narrativos que recuperan de otro modo complejas tradiciones universales y una cultura de la errancia productora de textos que inauguran cartografías culturales [...] desde una mirada original" (Manzoni, 2006: 14-15).

Tampoco se puede olvidar de la influencia del Infrarrealismo, ideológicamente parecido al Estridentismo mexicano de los años 20, en su manera de construir los relatos. En la opinión de José Promis, la literatura de Bolaño "busca manifestar un realismo visceral [una de las propuestas fundamentales del movimiento infrarrealista], una visión interior que pugna por exteriorizarse sin claudicar frente a órdenes que no emanen de ella misma, ofreciendo, en este sentido, una construcción de la realidad alternativa y rupturista por naturaleza" (Promis, 2003: 51).

Por último, Ignacio Echevarría habla de una nueva serie llamada "nueva narrativa hispanoamericana" constituida en torno al autor chileno. Sin embargo, la actitud de Bolaño ante esta idea fue bastante contradictoria, lo que expresó criticando a los supuestos miembros del grupo y separándose de su literatura mediante experimentación estructural y los acentos personales que no podían ser repetidos y crear una especie de serialidad. Tal vez, las palabras de Andrés Neuman que en uno de sus ensayos dedi- 
cados a Bolaño calificó su escritura como "desesperada", definen de la mejor manera posible el estilo del autor chileno:

Si tuviera que destacar uno de los múltiples dones literarios de Roberto Bolaño, creo que elegiría la desesperación. Lo que más me impresiona de él es eso: su fecunda desesperación por vivir, por escribir, por contar. Bolaño no narraba las historias, las necesitaba. Su escritura tiene una cualidad profundamente agónica y quizá por eso nos conmueve tanto, hable de crímenes o enciclopedias, de sexo o metonimias. Concuerdo con quienes opinan que la metaliteratura de Bolaño es más bien una apariencia, porque su referente último no es la literatura misma sino una moral vital. Esa pulsión vital se echa en falta en la gran mayoría de autores metaliterarios (Neuman, 2012: 321).

Pasando a la figura de Witoldo, como lo llamaban sus amigos argentinos, en sus textos también encontramos la constante persecución vanguardista de un estilo literario único e irrepetible:

[...] hoy iniciamos una nueva creación. Que esa creación sea única y verdadera, no una miserable imitación, una firma gratuita, una simple forma de hablar sin decir nada, sino un verdadero trabajo del espíritu a la búsqueda de su expresión. Creedeme: por raro e incluso alocado que yo sea, y aunque en verdad haya caído en una extraña frivolidad, al menos veo muy claro y sé que debemos abrir nuevos horizontes (Gombrowicz, 1972: 20).

Así pues, ¿qué características tiene el estilo del escritor polaco? Su estilo suele ser calificado como absurdo, grotesco, irónico e, incluso, paradójico. De esta manera lo define el propio Gombrowicz en Ferdydurke:

[...] edificar la obra sobre la base de partes sueltas -conceptuando la obra como una partícula de la obra- y tratando al hombre como una fusión de partes de cuerpo y partes de alma, mientras a la Humanidad entera la trato como a una mezcla de partes. Pero si alguien me hiciese tal objeción: 
que esta parcial concepción mía no es, en verdad, ninguna concepción, sino una mofa, chanza, fisga y engaño, y que yo, en vez de sujetarme a las severas reglas y cánones del Arte, estoy intentando burlarlas por medio de irresponsables chungas, zumbas y muecas, contestaría que sí, que es cierto, que justamente tales son mis propósitos (Gombrowicz, 1983: 72-73).

Por ello, sus novelas rompen con la narrativa convencional optando por complejos laberintos estéticos: hibridez formal (Blas Matamoro define su literatura como un "discurso-entre", al igual que el escritor es un "ser-entre"), continua subversión de las estructuras gramaticales, neologismos, repeticiones que expresan la tendencia del autor a ritualizaciones, deformación de géneros literarios (parodia de la Bildungsroman en Ferdydurke, caricatura de la epopeya tradicional polaca en Trans-Atlántico y de la novela detectivecsa en Cosmos), permanentes alusiones metalingüísticas, libre empleo de las mayúsculas, reemplazo de los verbos de pensamiento por verbos de movimiento, animalizaciones, juegos autorreferenciales, digresiones y monólogos interiores. A pesar de dichas innovaciones formales, el autor polaco también opta por cambios temáticos, ficcionalizando los principales conceptos del existencialismo ateo como la nada, la libertad o el vacío; abordando temas socialmente controvertidos: erotismo, homosexualidad, la promiscuidad femenina, perversiones sexuales; y empleando el humorismo atroz.

No obstante, en la opinión de varios críticos, el estilo gombrowicziano no es nada más que su forma de crear "el mito Gombrowicz", una estrategia autorial, también propia de Bolaño (Espinosa Hernández subraya que el realismo bolañiano es un gran proyecto literario estrechamente ligado a una estrategia autorial presente en las entrevistas del chileno y en su controvertida actividad ensayística, donde encontramos un sinfín de desmesuras, provocaciones y bromas). El propio escritor admitía que como cada artista era un ser egoísta en busca de renombre, un individualista que quería conseguir la fama tanto mediante polémicas con otros artistas como a través de las extravagancias estilísticas. Empero, pese a la búsqueda de reconocimiento, hay que acen- 
tuar que Gombrowicz fue un pensador insaciable fascinando por distintas filosofías que, a través de todos los mencionados antes recursos literarios, procuraba reflejar la complejidad de sus pensamientos, de su proceso mental complicado y diferente. Además, él mismo confesaba que su "libertad creadora excitante" provenía del distanciamiento hacia la Forma, lo que exigía alejarse de las fórmulas convencionales y comúnmente empleadas creando su propio estilo.

Otro punto de referencia común para ambos escritores es el rechazo, al menos inicial, de su obra dentro de sus respectivos círculos nacionales y/o literarios, de modo que tanto el autor chileno como el polaco, consiguieron el verdadero éxito de forma póstuma. Roberto Bolaño, sin duda, no formó parte de la Nueva Narrativa, conocida también como Generación NN o narrativa post dictadura, que surgió en Chile a principios de los años 90 y estaba fuertemente vinculada a la política editorial globalizadora y la instalación de grandes editoriales cuyo objetivo, por lo menos en teoría, fue apoyar a los autores nacionales. No obstante, dicha empresa fracasó por falta de un líder y una poética o manifiesto uniformes para todo el grupo, escasa calidad estética de los textos y en consecuencia falta de empeño en difundirlos por parte de las mismas editoriales.

En cuanto a los autores más recientes, estos vuelven a la estética de la narrativa chilena de la primera mitad del siglo XX, optando por el realismo, la causalidad y la linealidad de la trama, evitando preocupaciones de carácter estético y metatextual y rechazando cualquier tipo de nacionalismo. Ahora bien, dentro de este contexto, ¿dónde habrá que situar a Roberto Bolaño?

El autor chileno realmente surge como escritor en su propio país en el año 1996 con la publicación de La literatura nazi en América. No obstante, existe una especie de ignorancia de su persona y obra provocada por la feroz crítica acerca de la política literaria en Chile que Bolaño ejerce en la prensa:

Ahora bien: escribir -juro que lo leí en un periódico de Chileque hay que apresurarse a darle el Premio Nacional a Allende antes de que le den el Nobel me parece, no ya una tomadura 
de pelo desproporcionada, sino que acredita al autor del aserto como un ignorante de antología. ¿De verdad hay inocentes que piensan así? ¿Y los que piensan así son inocentes o simples botones de muestra de una estulticia que se ha apoderado no solo de Chile sino de Latinoamérica? [...] Los premios, los sillones (en la Academia), las mesas, las camas, hasta las bacinicas de oro son, necesariamente, para quienes tienen éxito o bien se comporten como funcionarios leales y obedientes. Digamos que el poder, cualquier poder, sea de izquierdas o de derechas, si de él dependiera, solo premiaría a los funcionarios. En este caso Skármeta es el favorito de lejos. Si estuviéramos en el Moscú neoestalinista, o en La Habana, el premio sería para Teitelboim (Bolaño, 2004: 102-103).

Dicha postura de rechazo acrecienta después de la publicación de Nocturno de Chile (2000) que hace referencias a la crítica literaria en la Era de Pinochet. Edmundo Paz Soldán, siguiendo las palabras de Rodrigo Fresán -“[...] aventuro una sospecha: Bolaño es uno de los escritores más románticos en el mejor sentido de la palabra" (Fresán, 2008: 287)- define estas intervenciones de Bolaño en esfera pública como reactivación del escritor romántico que lucha contra la injusticia y las normas arcaicas que prevalecen en el mundo literario. Como demuestra el artículo citado, Bolaño en varias ocasiones criticó cualquier compromiso ideológico y político-militante -aunque en su juventud fue trotskista y anarquista- afirmando que el único deber del literato consiste en escribir bien.

Asimismo, el autor chileno categóricamente rechazaba cualquier relación de su obra con la herencia del famoso boom latinoamericano ("No me siento heredero del boom de ninguna manera. Aunque me estuviera muriendo de hambre, no aceptaría ni la más mínima limosna del boom, aunque hay escritores que releo a menudo como Cortázar o Bioy. La herencia del boom da miedo" - Herralde, 2005: 95), alejándose todavía más de los círculos literarios hispánicos. Además, de manera recurrente criticaba el estado de la literatura latinoamericana actual, por lo cual, Lina Meruane denomina la literatura bolañiana como "máquina textual de guerra" que defiende a algunos de los consagrados por la crítica (Borges, Cortá- 
zar, Hernández, Piglia o Villoro, Aira y Pauls de su generación), ataca a ciertos autores como Allende, Sepúlveda o Donoso, y reivindica a otros (Parra, de Rokha, Lihn). No obstante, no se puede olvidar que esta imagen del escritor anti-sistema fue creada por el propio Bolaño para provocar y rebelarse ante el reconocimiento simbólico que obtuvo en los últimos años de su vida. Dicho reconocimiento significaba publicaciones en las más prestigiosas editoriales, buenas críticas, traducciones, conferencias, buenas ventas, respetabilidad todo lo que antes renegaba. Paz Soldán subraya que los ataques del escritor no siempre deberían ser tomados en serio: "[...] en Bolaño muchas veces había humor, el deseo de preservar el espíritu contestatario de los infrarrealistas, de seguir a Nicanor Parra en el espíritu de contradicción" (Paz Soldán, 2008: 26). Todas estas experiencias y opiniones personales que polarizaban el público y que el chileno transmitió tanto en los ensayos, charlas y entrevistas (aquí habrá que destacar el hecho de que la gran mayoría de sus entrevistas fue contestada por escrito; por tanto, se suele decir que ta mbién forman parte de su legado literario) como en su prosa y poesía, fundaron lo que César Aira llamaría un "mito personal del escritor", tan parecido al "mito Gombrowicz".

En el caso gombrowicziano, también observamos la feroz crítica de la anticuada y consagrada tradición literaria polaca. Desde su punto de vista, hay que modernizar la literatura nacional:

Deberíamos tener una literatura justamente opuesta a la que se ha escrito hasta ahora, tenemos que buscar un camino nuevo en oposición a Mickiewicz y a todos los "reyes de espíritu". [...] Pero lo más doloroso será atacar en sí mismo el estilo polaco, la belleza polaca, crear una mitología y unas costumbres nuevas cuya fuente estará en aquella otra mitad nuestra, el polo opuesto; ampliar y enriquecer nuestra belleza de manera que el polaco pueda gustarse a sí mismo en dos imágenes contradictorias: como el que es actualmente y como el que destruye en sí mismo al que es (Gombrowicz, 2005: 165).

Por tanto, cuando en 1951 publica Trans-Atlántico, enfurece la emigración polaca -criticada de manera atroz en la novela-, de modo que el libro tiene más detractores que admiradores. En 
Polonia, Trans-Atlántico aparece seis años después gracias al corto período de deshielo político, pero tampoco consigue el esperado éxito por ser un texto más bien ininteligible. Pese a que la novela suele ser interpretada como una fuerte crítica de Polonia y de los polacos, en una de las últimas entrevistas concedidas a Dominique de Roux, Witoldo confiesa:

Sabe, algunos de mis compatriotas me consideran un autor excepcionalmente polaco, y es posible que sea a la vez muy antipolaco y muy polaco, quizás polaco por antipolaco; porque el polaco se realiza en mí sin premeditación, libremente, y en la medida en que se vuelve más fuerte que yo. [...] No me sorprendería en absoluto que ese humor negro, en Trans-Atlántico, fuera la expresión, casi al margen de mi voluntad, del orgullo y de la libertad polacas (Gombrowicz, 1991: 114)

Asimismo, parece preciso abordar el tema de Gombrowicz como parte de la tradición literaria argentina, presentando las ideas de Juan José Saer y Ricardo Piglia. Los dos escritores, recurriendo a varias analogías entre la cultura polaca y la argentina (fundamentalmente la Inmadurez y el carácter periférico de ambas naciones), se atreven a afirmar que la presencia de Gombrowicz en el campo literario argentino (y sobre todo la inusual traducción de Ferdydurke) dejó huellas indudables en la novela moderna de este país latinoamericano, de modo que el autor polaco forma parte del canon literario argentino. Ricardo Piglia ve la clara relación entre Gombrowicz y la literatura argentina admitiendo que "la novela argentina sería una novela polaca; [...] una novela polaca traducida a un español futuro, en un café de Buenos Aires, por una banda de conspiradores liderados por un conde apócrifo. Toda verdadera tradición es clandestina y se construye retrospectivamente y tiene la forma de un complot" (Piglia, 1987). La alusión a la famosa traducción de Ferdydurke en el Café Rex es más que obvia. Piglia, haciendo referencias a la tesis de Deleuze y Guattari, según la cual una traducción influye en el lenguaje de la literatura nacional, considera la traducción de la novela gombrowicziana un momento transcendental para el devenir de la tradición literaria en Argentina. Es más, entiende dicha traducción 
como la experiencia de vivir en dos realidades lingüísticas distintas que, desde su punto de vista, es una de las características de la novela moderna, traducida $-y$, por tanto, transformada- constantemente a todas las lenguas posibles. Sin embargo, es un reconocimiento que tardó en llegar. Gombrowicz no pertenecía a la élite intelectual de la Buenos Aires de los años 40 y 50 , sino que desde el principio de su exilio se alejó tanto de la emigración polaca como de los círculos literarios porteños y creó a su alrededor un ambiente de extrañeza. Su postura de alejarse del mundo cultural bonaerense tuvo dos causas fundamentales: el desconocimiento de español y una personalidad intratable, aunque él mismo nunca quiso reconocerlo, echando la culpa al "Parnaso" intelectual, encabezado por Borges que no entendía su originalidad:

Después de mi éxodo de Argentina se creó algo así como una leyenda melodramática; resulta que el escritor reconocido hoy en Europa vivió en Argentina, humillado, despreciado y rechazado por el Parnaso local. Todo eso es falso. Yo prefería voluntariamente no mantener relaciones con el Parnaso, porque los medios literarios de todas las latitudes geográficas están integrados por seres ambiciosos, susceptibles, absortos en su propia grandeza. [...] Creo que por las mismas razones el Parnaso no se apresuró a trabar relaciones más estrechas conmigo [...] un polaco, un desconocido en París, autor de cierta obra, con gustos literarios demasiado paradójicas, sospechoso y excéntrico (Gombrowicz, 2005: 10-11).

No cabe duda de que la estética gombrowicziana difería de las propuestas de Borges en casi todos los aspectos, con lo cual, no existía la posibilidad de entablar cualquier amistad entre el polaco, admirador de lo bajo y cotidiano, y la intelectualidad argentina que tendía a filosofar y, ante todo, valoraba lo estético. Aquí merece la pena admitir que Gombrowicz fue consciente de la necesidad de entrar en la vida intelectual porteña, ya que como escritor joven y prácticamente desconocido, también en Polonia, no tuvo otra posibilidad de seguir desarrollando su carrera de literato. No obstante, como ya ha sido comentado, no compaginaba con los modelos intelectuales porteños $y$, además, no era capaz de 
funcionar dentro de cualquier grupo entendido por él como una institución que limita y oprime la libertad artística. Empero, hay que reconocer que Argentina se convirtió para Gombrowicz en una suerte de segunda patria, a pesar de que durante muchos años la crítica y los mismos círculos literarios de este país latinoamericano despreciaban al escritor, con excepciones del grupo de sus amigos: Virgilio Piñera, Juan Carlos Gómez (El Goma), Mariano Betelú, Alejandro Rússovich y algunos otros.

El siguiente lazo entre ambos autores es el carácter autoficcional de su narrativa. En la opinión de Roberto Bolaño los géneros memorialísticos y autobiográficos son los más engañosos por ser un intento de justificarse ante el público mediante mentiras y disimulos. Además, los considera una pérdida de tiempo del narrador y un mero "ejercicio de melancolía". En una de las múltiples entrevistas que concedió Roberto Bolaño, admitió que prefiere "[...] la literatura, por llamarle de algún modo, teñida ligeramente de autobiografía, que es la literatura del individuo, la que distingue a un individuo de otro, de la literatura de nosotros, aquella que se apropia impunemente de tu yo, de tu historia [...]" (Swinburn, 2003) - de esta manera reconoce ser partidario de la autoficción y lo admite en la entrevista concedida a Carmen Boullosa:

[...] los autorretratos suelen ser muy malos, incluso los autorretratos poéticos, que a simple vista parece una disciplina literaria más apta para el autorretrato que la narrativa. ¿ $\mathrm{Si}$ mi obra es autobiográfica? En cierto sentido, ¿cómo podría no serlo? Toda obra, incluida la épica, en algún momento es autobiográfica (Boullosa, 2006: 111).

En el ensayo dedicado a la novela Soldados de Salamina escrita por su amigo Javier Cercas, así comenta el hecho de que uno de los personajes tiene su nombre y apellido:

La tercera parte [de Soldados de Salamina] se centra en el desconocido soldado republicano que le salvó la vida a Sánchez Mazas, y aquí aparece un personaje nuevo, un tal Bolaño, que es escritor y chileno y vive en Blanes, pero que 
no soy yo, de la misma manera que el Cercas narrador no es Cercas, aunque ambos son posibles e incluso probables (Bolaño, 2004: 177).

Con estas palabras, Bolaño admite que la autoficción es para él un juego cuyo objetivo es provocar, despertar curiosidad - aunque niega que el Bolaño personaje es él, al mismo tiempo admite que es un hecho "incluso probable". Es una herramienta que a menudo se puede encontrar en la narrativa bolañiana, un tipo de juego que crea el chileno, tal vez, una trampa en la que suele caer el lector. Por tanto, sus novelas no son de fácil lectura, requieren cierto esfuerzo y una gran colaboración por parte del lector. Varios críticos, entre ellos Madariaga Caro, consideran la literatura del escritor chileno un rompecabezas con una serie de pistas que se le ofrece al lector para invitarlo a indagar acerca de la veracidad de lo contado, para animarlo a convertirse en un detective como lo son los protagonistas de Los detectives salvajes. Así pues, su literatura, denominada por críticos como híbrida, transgenérica, entremezcla ensayo, autobiografía, ficción, periodismo, diario íntimo, libro de viajes, crítica literaria e historiografía entre otros, rompiendo con la dominante narrativa tradicional y creando dudas en cuanto a su carácter ficcional/no ficcional por la casi obsesiva presencia de un alter ego del autor que incita al lector a buscar relación entre escritor y sujeto de la enunciación.

En el caso del autor polaco, Enrique Vila-Matas en el artículo "Perfil: Witold Gombrowicz" asegura que para entender a Gombrowicz hay que leer su obra que, a un tiempo, es su vida, su intimidad. Afirma que está convencido de que la vida y la literatura eran para el autor polaco una misma cosa inseparable: "En él cada palabra se encarnaba en su vida, trabajó mucho sobre sí mismo creando su propio estilo. Su obra -oscura, sonámbula y extravagante- era la reencarnación de su propia personalidad" (Vila-Matas, 2004: 86).

Así pues, Gombrowicz presenta una modalidad literaria a la que denomina "literatura privada" y la desarrolla en casi toda su obra, especialmente en Diario. No obstante, dicha escritura de la intimidad no responde a las expectativas del lector: en vez de las historias íntimas de su vida, el autor polaco trata sobre problemas 
universales, presenta acontecimientos más bien banales de la vida cotidiana y si ya decide aludir a sus experiencias personales, lo hace en forma de alusiones de corte filosófico e intelectual. Su manera de redactar el Diario y el carácter mismo del texto, lo explican los conceptos de la Forma y la Inmadurez, presentes siempre en la vida artística de Gombrowicz.

De acuerdo con la primera idea, cualquier texto, aunque supuestamente íntimo, nunca es una expresión puramente individual, puesto que copia voces y estructuras ajenas, con lo cual es algo artificial como todo ser humano: "Ser una persona equivale a no ser nunca uno mismo" (Gombrowicz, 1982: 12). Interpretando el término en el ámbito social, lo privado no puede existir sin definir antes lo público, de modo que los dos polos siempre se van a compenetrar mezclando ambas modalidades. En cuanto al concepto de la Inmadurez, el hombre se ve obligado a ocultarla y expresar únicamente la Madurez en forma de ficciones, puesto que no quiere y/o no es capaz de mostrar su faceta de inexperto, considerada uno de los defectos vergonzosos. Por esta razón, Gombrowicz declara:

La persona, torturada por su máscara, se construye en secreto, para su uso privado, una especie de subcultura: un mundo hecho con los desperdicios del mundo cultural superior, un dominio de la ratería, de los mitos informes, de las pasiones inconfesadas... un secundario dominio de compensación. Es allí donde nace una poesía vergonzosa, una cierta comprometedora hermosura... (Gombrowicz, 1982: 13)

Parecidos a alguien que temiese su propia desnudez, echamos mano a cualquier vestimenta a nuestro alcance, aun la más grotesca, y así se crea ese mundo hecho de indolencia, insuficiencia, no seriedad e irresponsabilidad, mundo de la subcultura, de las formas caducadas, malogradas, desviadas e impuras, donde se desarrolla nuestra vida íntima (Gombrowicz, 1983: 263).

Así pues, la escritura gombrowicziana es un lugar donde muestra dichos conflictos que provoca la Forma y la Inmadurez; es un 
espacio donde puede interpretar distintos papeles entremezclando lo autobiográfico - entendido como expresión de la Inmadurezcon lo ficcional, que a su vez procura esconder lo inmaduro. Asimismo, hay que agregar que este carácter contradictorio es propio de la personalidad gombrowicziana, ya que el escritor siempre buscaba extrañar y sorprender asumiendo diversos puntos de vista que, además, le permitían escapar de una Forma concreta.

Igualmente, hay que subrayar que su escritura -aunque denominada como privada por el propio autor- es en realidad completamente pública, dado que no sirve para transmitir la realidad personal de Gombrowicz, sino que funciona como una herramienta para crearse frente a los demás. En resultado existe como máscaras que se convierten en una serie de rompecabezas que el lector de su obra tiene que resolver. Por supuesto, el autor polaco no quiere que estos enigmas sean demasiado fáciles, debido a lo cual, mediante el recurso de la autoficción, se aleja aún más de lo privado, haciendo del encuentro con el público lector algo dificultoso de entender e interpretar, incluso incómodo. Aquí merece la pena citar al propio Gombrowicz: "En literatura, la sinceridad no conduce a nada. He aquí otra de las antinomias dinámicas del Arte: cuanto más artificiales somos, más probabilidades tenemos de llegar a la franqueza" (Gombrowicz, 2005: 112).

Por último, habrá que hacer referencia a la experiencia del exilio que compartieron los dos autores. Roberto Bolaño por su larga estadía en México y España, sus narraciones ambientadas fundamentalmente en estos dos países y su fuerte crítica de la situación política y social en Chile, por muchos es considerado un autor mexicano o español, de todas formas, un extranjero. El mismo Bolaño se sitúa dentro del concepto de la llamada "neonacionalidad":

[...] yo no soy propiamente un latinoamericano. Yo he vivido muchísimos años en España. Yo aquí no me siento extranjero, eso sin ninguna duda. De hecho, cuando estoy en Latinoamérica todo el mundo me dice: "Pero si tú eres español", porque para ellos hablo como un español. Para un español, no. Un español ve claramente que yo soy un sudamericano. 
Y ese estar en medio, no ser ni latinoamericano ni español, a mí me pone en un territorio bastante cómodo, en donde puedo fácilmente sentirme tanto de un lado como de otro (Gras Miravet, 2000: 57).

En este contexto, Ignacio Echevarría hace hincapié en el carácter transgenérico de la narrativa y poesía bolañianas como consecuencia de la indeterminación de la realidad en la que vivía, la "extraterritorialidad" de George Steiner que consiste principalmente en falta de conciencia local y/o nacional y estabilidad lingüística. Como admitió el autor chileno, es "un territorio bastante cómodo", dado que le permite alejarse de la poética del Boom donde el exotismo latinoamericano tenía un papel fundamental. Además, en la opinión de Echevarría, la extraterritorialidad es para Bolaño cierta forma de entenderse a sí mismo como escritor ante la paradoja de querer y no querer ser autor latinoamericano, querer y no querer escribir sobre Chile.

Sin embargo, la condición del exiliado -aunque cabe destacar que Bolaño rechazaba este concepto- no le impide abordar en su producción literaria el tema de la dictadura militar de Pinochet (1973) que retrata fundamentalmente en Nocturno de Chile, donde, a través del vínculo entre el ser humano / la literatura y el poder represivo y destructivo, se manifiesta claramente la experiencia del golpe militar; incluso se puede afirmar que la violencia y la muerte en la narrativa bolañiana, relacionadas a las mencionadas circunstancias políticas e históricas, son unos de los temas recurrentes. No obstante, no es la única influencia del contexto histórico en el cual creció. Paula Aguilar considera la creación del mito Bolaño -el escritor rebelde que rompe con la tradición, se opone a los consagrados y revisa el papel de la política en el mundo literario- el efecto de la experiencia dictatorial y del desarraigo. Así pues, analiza su literatura como una de las formas de tratar la memoria de la dictadura, que todavía parece ser un problema social no solucionado, o una de las maneras de posicionar al escritor dentro del conflicto, un escritor que debería enfrentarse a lo sucedido y responder a la pregunta cómo y desde dónde contar la historia. Por esta razón, numerosos críticos afirman que la narra- 
tiva bolañiana es comprometida con la política latinoamericana, principalmente la chilena, lo que reconoce el mismo escritor en varias entrevistas:

[...] en gran medida todo lo que he escrito es una carta de amor o de despedida a mi propia generación, los que nacimos en la década del cincuenta y los que escogimos en un momento dado el ejercicio de la milicia, en este caso sería más correcto decir la militancia, y entregamos lo poco que teníamos, lo mucho que teníamos, que era nuestra juventud, a una causa que creíamos la más generosa de las causas del mundo y que en cierta forma lo era, pero que en realidad no lo era (Bolaño, 2004: 37).

Asimismo, Valeria de los Ríos (2008: 253) emplea la metáfora de Bolaño como "cartógrafo salvaje" para acentuar la complejidad de mapas cognitivos creados por el escritor que reflejan la movilidad identitaria y espacial que caracteriza su literatura. Entretanto, Carreras Rabasco (2011: 164) habla del exilio ideológico de Bolaño cuyas huellas son visibles en la marginalidad de sus personajes, el desamparo y la desolación que sienten al reconocer la derrota de los ideales que propugnaban. Por último, según Paz Soldán (2008: 27), la literatura de Bolaño es una aventura vitalista, una búsqueda de sí mismo provocada por la mencionada neonacionalidad que desde el principio fue condenada a fracasar, como fracasó la revolución y la ideología utópica del joven chileno.

El tema de exilio en caso de Witold Gombrowicz siempre ha despertado polémicas en el ámbito polaco, fundamentalmente a causa de la decisión del escritor de quedarse en la ciudad bonaerense ante el estallido de la Segunda Guerra Mundial, lo que fue revelado relativamente hace poco. También la relación del escritor con Argentina y sus círculos literarios siempre fue ambivalente. Por un lado, Gombrowicz en los Diarios a veces emplea el pronombre inclusivo "nosotros" para referirse a la literatura rioplatense; por otra parte, deja claro que es un extranjero, tal vez un "argentino ocasional" incapaz de comunicarse en español (“[...] carezco de autoridad y mi castellano es un niño de pocos años que apenas sabe hablar. No puedo hacer frases potentes, ni 
ágiles, ni distinguidas, ni finas [...]" - Gombrowicz, 2009: 12), con lo cual, no podía sentir ningún lazo extraordinario con el país de acogida.

Por ello, la crítica sitúa a Witoldo, al igual que a Roberto Bolaño, dentro de la idea de extraterritorialidad (en caso de Gombrowicz también lingüística) de Steiner. El propio escritor polaco se inscribe en dicho concepto cuando, tal como el autor chileno, se pronuncia en contra de cualquier tipo de colectivismos nacionales y deberes patrióticos propios de estos (y lo que demuestra tomando la decisión de quedarse en Argentina), dado que un individuo convertido en masa, según Gombrowicz, actúa conforme a las órdenes de un líder, lo que suele conducir a crímenes y crueldades comunes dirigidos hacia el enemigo: el Otro privado de su humanidad, el diferente frente a una comunidad homogénea. La Patria es, desde su punto de vista, una creación ilegítima, invasiva y existe como un concepto completamente abstracto. Por este motivo, el polaco se distanciaba de la política -como uno de los temas alternativos cuyo fin consiste en desviar la atención de los problemas realmente importantes que afrontan filosofía y literatura- y no quería ser considerado un escritor comprometido, vinculado a cualquier opción política (empero, Piotr Kulas subraya que Gombrowicz a menudo se pronunciaba sobre asuntos políticos, aunque siempre abordando cuestiones generales y universales). Él mismo se denominaba como revolucionario, pero unía la revolución al Arte: "Me importa mi arte y él necesita sangre generosa, cálida... el Arte y la rebelión son casi lo mismo. Soy revolucionario por ser artista y en la medida en que lo soy" (Gombrowicz, 2003: 94).

Pese a la mencionada antes postura antinacionalista, Mikel Iriondo (2007: 76) asegura que el tema de Polonia -o más bien la manipulación de la memoria nacional con fines patrióticos-es, junto a otras derivas de la Forma, uno de los asuntos fundamentales tratados en la obra gombrowicziana. No cabe duda de que su ascendencia - una familia de rango aristocrático, aunque bastante dudoso- comprendida como una de las Formas opresoras, dejó huella en la ideología del joven Gombrowicz que veía las culturas locales como aniquiladoras de la individualidad. Por tanto, como 
ya ha sido mencionado, criticaba de modo ostensible el "delirio romántico" de la Polonia sármata e inmadura, arraigada en doctrinas y tradiciones de los siglos pasados:

Ataqué a la vez el principio mismo de autoadoración nacional. Dije que si una nación verdaderamente madura debe juzgar con moderación sus propios méritos, una nación verdaderamente viva debe aprender a menospreciarlos, tiene que mostrarse altiva ante todo lo que no sea su presente y su devenir contemporáneo [...]. Nada lo que es propio debe impresionar al hombre; de tal modo que, si nos impresiona nuestra grandeza o nuestro pasado, esa es la prueba de que aún no lo llevamos en la sangre (Gombrowicz, 2005: 26).

¿La historia? Es necesario que nos convirtamos en iconoclastas de nuestra propia historia basándonos únicamente en nuestro presente, ya que precisamente la historia constituye nuestra tara hereditaria, nos impone la falsa imagen que tenemos de nosotros mismos y nos obliga a parecernos a una deducción histórica en lugar de vivir con nuestra propia realidad. Pero lo más doloroso será atacar en sí mismo el estilo polaco, la belleza polaca, crear una mitología y unas costumbres nuevas cuya fuente estará en aquella otra mitad nuestra, el polo opuesto; ampliar y enriquecer nuestra belleza de manera que el polaco pueda gustarse a sí mismo en dos imágenes contradictorias: como el que es actualmente y como el que destruye en sí mismo lo que es (Gombrowicz, 2005: 165).

Sin embargo, pese a su personalidad antinacionalista, Witoldo abordaba en sus obras el tema de Polonia y se consideraba a sí mismo como un escritor polaco: "Yo debo escribir en polaco, porque esta es mi lengua, la domino. Sin embargo, podría escribir en otra lengua si la dominara como domino el polaco. Pero yo soy un escritor polaco y por eso tengo que expresarme en polaco" (citado por Matyjaszczyk-Grenda, 2002:306).

A modo de conclusión, hay que constatar que existen claras similitudes entre la vida y la obra de Roberto Bolaño y Witold Gombrowicz. Ambos reniegan de las tipologías establecidas, con- 
virtiéndose en autores de referencia, figuras de culto al estilo de poètes maudits para una parte de crítica y, ante todo, para algunos grupos de jóvenes (en este lugar, merece la pena subrayar que en ambos casos el reconocimiento por parte de la crítica y de los lectores tardó en llegar, de modo que Bolaño, al igual que Gombrowicz, consiguió el verdadero éxito de forma póstuma). Asimismo, ambos son escritores inclasificables desde el punto de vista estilístico y critican de forma atroz las posturas serviles del artista respecto a la política y las corrientes literarias vigentes. Además, en los dos casos destaca la condición de exiliado que marcó sus vidas, forzándoles a vivir en condiciones económicas más bien precarias; no obstante, aunque los dos autores se inscriben dentro del concepto de extraterritorialidad de Steiner, en sus textos aparecen claras referencias a sus patrias correspondientes. Como último, hay que destacar el hecho de emplear de modo recurrente la herramienta de la autoficción, el rasgo distintivo de sus poéticas. Así pues, las figuras de Bolaño y Gombrowicz funcionan como una especie de vínculo entre las tradiciones literarias polaca e hispánica, aunque, a primera vista, estas parecen ser dos mundos opuestos.

\section{BIBLIOGRAFÍA}

Bolaño, R. (2004), Entre paréntesis. Ensayos, artículos y discursos, Barcelona: Anagrama.

Boullosa, C. (2006), “Carmen Boullosa entrevista a Roberto Bolaño”, en: C. Manzoni (ed.), Roberto Bolaño: la escritura como tauromaquia, Buenos Aires: Corregidor, 105-113.

Carreras Rabasco, A. (2011), "Roberto Bolaño, la memoria antiheroica del exilio chileno", América sin Nombre 16: 160-170.

de los Ríos, V. (2008), "Mapas y fotografías en la obra de Roberto Bolaño", en: E. Paz Soldán, G. Faverón Patriau (eds.), Bolaño salvaje, Barcelona: Candaya S.L., 237-258.

Espinosa Hernández, P. (2003), “Estudio preliminar”, en: P. Espinosa Hernández (ed.), Trerritorios en fuga. Estudios críticos sobre la obra de Roberto Bolaño, Santiago de Chile: FRASIS editores, 13-32. 
Fresán, R. (2008), “El samurái romántico”, en: E. Paz Soldán, G. Faverón Patriau (eds.), Bolaño salvaje, Barcelona: Candaya S.L., 293-303.

Gombrowicz, W. (1972), Autobiografía sucinta, textos y entrevistas, Barcelona: Anagrama.

Gombrowicz, W. (1983), Ferdydurke, Buenos Aires: Sudamericana.

Gombrowicz, W. (1991), Testamento, Barcelona: Anagrama.

Gras Miravet, D. (2000), “Entrevista con Roberto Bolaño”, Cuadernos Hispanoamericanos 604: 53-68.

Gombrowicz, W. (2005), Diario 1953-1969, Barcelona: Seix Barral.

Gombrowicz, W. (2003), Diario argentino, Buenos Aires: Adriana Hidalgo.

Gombrowicz, W. (2009), Contra los poetas, Madrid: Sequitur.

Gombrowicz, W. (1982), La seducción (Pornografía), Barcelona: Seix Barral.

Herralde, J. (2005), Para Roberto Bolaño, Bogotá: Villegas Editores.

Iriondo Aranguren, M. (2007), “Witold Gombrowicz. La inmadurez, la forma y otras consideraciones", Enrahonar 38/39: 69-88.

Manzoni, C. (2006), "Prólogo. La escritura como tauromaquia”, en: C. Manzoni (ed.), Roberto Bolaño: la escritura como tauromaquia, Buenos Aires: Corregidor, 13-15.

Matyjaszczyk-Grenda, A. (2002), "Witold Gombrowicz: el problema de la identidad de un escritor polaco en el exilio", Revista de Filología Románica 19: 301-307.

Neuman, A. (2012), “La fuente y el desierto”, en: A. López Bernasocchi, J. M. López de Abiada (eds.), Roberto Bolaño. Estrella cercana. Ensayos sobre su obra, Madrid: Editorial Verbum, 317-322.

Paz Soldán, E. (2008), "Roberto Bolaño: literatura y apocalipsis”, en: E. Paz Soldán, G. Faverón Patriau (eds.), Bolaño salvaje, Barcelona: Candaya S.L., 11-30.

Piglia, R. (1987), “¿Existe la novela argentina? Borges y Gombrowicz”, Espacios de Crítica y Producción 6, https://pl.scribd.com/document/328067747/ Existe-La-Novela-Argentina (acceso: 6.05.2017).

Promis, J. (2003), “Poética de Roberto Bolaño”, en: P. Espinosa Hernández (ed.), Trerritorios en fuga. Estudios críticos sobre la obra de Roberto Bolaño, Santiago de Chile: FRASIS editores, 47-63.

Swinburn, D. (2003), “Catorce preguntas a Bolaño”, El Mercurio, 2 de marzo, http://ysinembargo.com/uebi/2010/01/catorce-preguntas-a-roberto-bolano (acceso: 10.05.2017).

Vila-Matas, E. (2004), “Perfil: Witold Gombrowicz”, Letras Libres 39: 82-86.

Roberto Bolaño y Witold Gombrowicz... 